\title{
Effect of void former shapes on one-way flexural behaviour of biaxial hollow slabs
}

\author{
R. Sagadevan ${ }^{1}$ B. N. Rao ${ }^{1}$
}

Received: 19 November 2018 / Accepted: 6 June 2019 / Published online: 19 June 2019

(c) The Author(s) 2019

\begin{abstract}
The Two-way hollow slab system (biaxial voided slab) is an innovative slab system, being adopted all over the world as an alternate for the conventional solid slab. It reduces the self-weight up to 50\% in comparison with solid slabs without significant change in its structural performance. The voided slab consists of void formers in shapes like spherical, donut, and cuboid. Experimental and analytical investigations were carried out to study the behaviour of biaxial voided slab under one-way flexure. Voided slab specimens were prepared and tested with two different shapes of voids namely sphere and cuboid, which were manufactured using recycled polypropylene. Comparison of experimental and analytical studies showed that the ultimate load-carrying capacity of voided slabs was higher or similar to that of solid slab. An analytical study was carried out using the yield line analysis in conjunction with Indian Standards. It was found that the capacity of voided slab can be estimated by yield line analysis. The flexural stiffness of voided specimen is approximately $50 \%$ lesser in comparison with solid slab of identical dimensions and reinforcement at yield stage. The reduction in flexural stiffness is mainly due to the presence of void former and the maximum void ratio at a section defines the flexural stiffness of the voided slab. Nevertheless, the deflection is under serviceable limit for both the specimens for $75 \%$ of ultimate load. Ultimately, it is found that the behaviour of voided slabs under one-way flexure can be predicted by provisions of Indian Standards with necessary correction for loss of cross-section caused by voids.
\end{abstract}

Keywords Biaxial voided slab $\cdot$ Sphere-shaped void $\cdot$ Cuboid-shaped void $\cdot$ One-way flexure $\cdot$ Yield line analysis

\section{Introduction}

Biaxial voided slab is reinforced concrete slab with void formers made of shapes like sphere, cuboid, and donut (BubbleDeck Technology 2008; Chung et al. 2010; Kim et al. 2011; Daliform Group 2014) and placed in the middle of slab in between the top and bottom of the reinforcing mesh. It reduces the self-weight of slab up to $50 \%$ in comparison with conventional solid slab without any significant change in its structural performance (Björnson 2003; Harding 2004). For example, the biaxial voided slab reduces selfweight by $44 \%$ in comparison with the solid slab of the same

\footnotetext{
B. N. Rao

bnrao@iitm.ac.in

R. Sagadevan

sagadevan.ceg@gmail.com

1 Structural Engineering Laboratory, Department of Civil Engineering, Indian Institute of Technology Madras, Chennai 600036, India
}

flexural capacity (BubbleDeck Technology 2008). This system renders an overall economical and efficient floor system in construction; it is eco-friendly as the void former is made of recycled plastic.

Experimental or analytical and numerical studies were conducted to evaluate the one-way flexural capacity of biaxial voided slab with different shapes of void formers. These studies provided evidence that biaxial voided slabs have slightly lower stiffness and similar strength compared to that of solid slab (BubbleDeck Technology 2008; Kim 2011; Ibrahim et al. 2013; Valivonis et al. 2014). The slab with donut-shaped void showed almost similar flexural capacity to that of solid slab. The material properties and strength of donut-shaped void highly affect the flexural strength of the voided slab (Kim et al. 2011). The flexural stiffness of spherical-shaped voided slab is $80-90 \%$ of solid slab, however, the void slab showed the same flexural strength as that of solid slab (Midkiff 2013).

The present study focusses on the effect of void shapes on one-way flexural capacity of biaxial voided slabs. The 


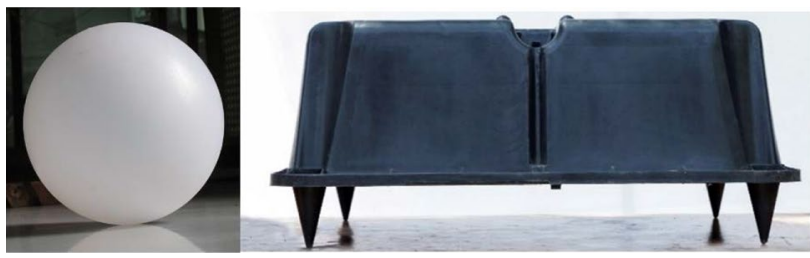

Fig. 1 Single unit sphere and cuboid void former

chosen void shapes for this investigation were sphere and cuboid which were manufactured using recycled polypropylene. The four-point bending test was conducted to study the effect of void and its shape on one-way flexural capacity of the slab and then, the obtained experimental results were compared with results obtained by yield line analysis (YLA) in conjunction with provisions given in Indian Standard 456 (IS 456 2000). Furthermore, the behaviour of voided slab was compared with that of the solid slab of the same crosssectional dimension and reinforcement ratio.

\section{Experimental study}

\section{Configuration of voided slab specimens}

The one-way flexural test helps to investigate the application of voided slab as an alternate to conventional solid slab. The structural behaviour of slab systems was studied in terms of load versus deflection behaviour, crack pattern, load-carrying capacity, flexural stiffness, deflection profile, load versus strain behaviour of bottom reinforcement and concrete surface along the depth of slab, and displacement-ductility ratio.

\section{Details of void formers}

Voids were created in the slab specimens using sphere- and cuboid-shaped void formers (Fig. 1). The sphere void former is a spherical-shaped hollow plastic ball of diameter $180 \mathrm{~mm}$ and wall thickness of $3 \mathrm{~mm}$ and it was manufactured specially for this study. The void former is kept in position with help of top and bottom reinforcement mesh with $25 \mathrm{~mm}$ clear cover at bottom; it is placed in such a way that the centre to centre spacing of void former is $210 \mathrm{~mm}$. The cuboidshaped void former (U-Boot Beton ${ }^{\circledR}$ ) which is commercially available in India was used in this study; these types of voids do not have any sharp edges. The average plan dimension of the void former is $475 \mathrm{~mm} \times 475 \mathrm{~mm}$. The elevator feet of height $50 \mathrm{~mm}$ was provided at the bottom face of four corners to place the void former at the centre of slab. The cuboid-shaped void former was placed in such a way that the centre to centre spacing is $600 \mathrm{~mm}$. Its depth and clear cover (at top and bottom) were $160 \mathrm{~mm}$ and $50 \mathrm{~mm}$, respectively.

\section{Details of test specimens}

Two types of voided slab specimens, one with a sphereshaped void and another with a cuboid-shaped void were cast and tested. The dimensions of test specimens were $3300 \mathrm{~mm} \times 1500 \mathrm{~mm} \times 260 \mathrm{~mm}$. The flexural behaviour of the slab was largely influenced by the tensile reinforcement provided in longitudinal and transverse directions (Matešan et al. 2012). To ensure flexure failure dominating shear failure, minimum reinforcement was provided as mesh in longitudinal and transverse directions. Fe 500D grade steel confirming to IS 1786 (2008) and M 20 grade concrete confirming to IS 456 (2000) were used. Figure 2 showed detailed specifications about the test specimens such as plan dimension, cross-section, reinforcement details and position of void formers.

\section{Material properties of test specimens}

Ready-mix concrete obtained from same batch (or mix) was used to cast the test specimens. The characteristic compressive strength $\left(f_{c k}\right)$ specified for $150 \mathrm{~mm}$ cube at 28 days is $25 \mathrm{~N} / \mathrm{mm}^{2}$ that corresponds to the mix proportion specified in Table 1. Six concrete cube specimens of the size $150 \mathrm{~mm}$ were cast and cured under similar exposure condition as that of slab specimens. The compressive strength tests of the cube specimen were performed along with the testing of slab specimens. The observed average strength of the cube specimen is given in Table 1. Tensile tests of reinforcements were conducted and the observed properties are summarised in Table 2.

\section{Experimental test setup and instrumentation}

\section{Test setup}

Four-point bending test was conducted to study oneway flexural behaviour of the voided slab. Figure 3a, b shows the schematic and actual test setup, respectively. Load was applied through a steel plate of the size $1500 \mathrm{~mm} \times 80 \mathrm{~mm} \times 16 \mathrm{~mm}$ as a patch load to avoid localised pre-mature shear failure (Fig. 4a). Two $500 \mathrm{kN}$ capacity pseudo dynamic hydraulic actuators were used to apply the loads. The slab specimens were supported by hinge at one end and roller at the other end at their edges, which is located $150 \mathrm{~mm}$ from specimen edges along short span directions by a line-type reaction hinge of length $1500 \mathrm{~mm}$. 

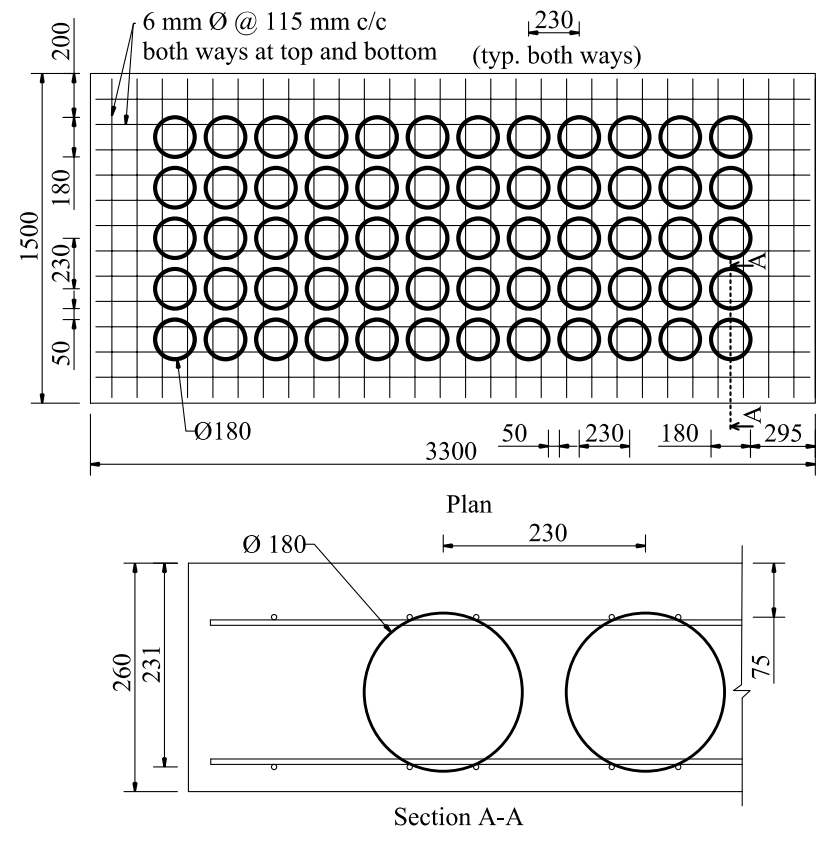

(a)
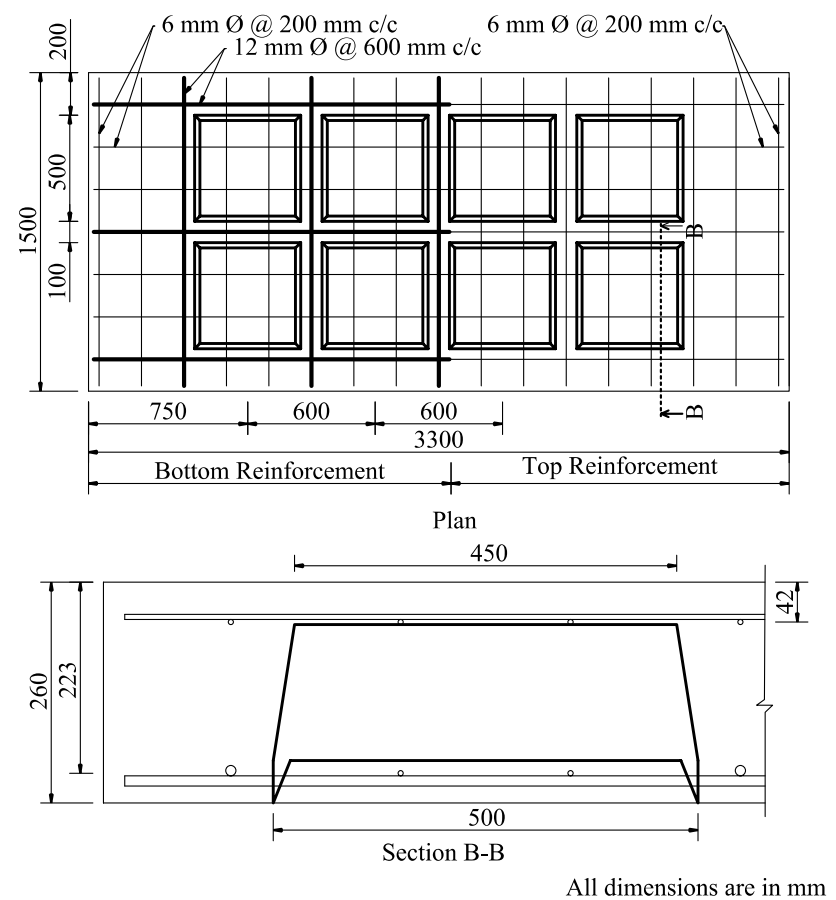

(b)

Fig. 2 a Details of specimen with sphere-shaped void former. b Details of specimen with cuboid-shaped void former

\section{Instrumentation}

Applied loads, deflections, and strain in reinforcements and concrete surface were measured through appropriate instruments. Load cells with the capacity of $1000 \mathrm{kN}$ were used to measure the applied loads. Three linear variable differential transformers (LVDTs) with measurement range of $\pm 100 \mathrm{~mm}$ were used to measure the deflections at mid-span and under point of application of loads. The concrete surface strain along the depth of slab was measured at front face of the slab in elevation using three LVDTs with measurement range of $\pm 20 \mathrm{~mm}$. Figure $4 \mathrm{~b}, \mathrm{c}$ shows the schematic arrangement of LVDTs. Strain in the bottom reinforcements located at the centre of slab specimens was measured by strain gauges with $10 \mathrm{~mm}$ gauge length. Strain gauges were provided in longitudinal and transverse directions of bottom reinforcements as shown in Fig. 4b. A data acquisition system was used to obtain real-time experimental data which had the facility to record the load, deflection, and strain simultaneously.

\section{Testing procedure}

Displacement controlled monotonic tests were performed with two pseudo dynamic hydraulic actuators. Equal load distribution across each actuator was ensured by synchronising the actuators and operating with a single master control system. The rate of loading was $0.05 \mathrm{~mm} / \mathrm{s}$. To ensure the safety of measuring and loading devices, the tests were terminated when the load was dropped suddenly.

\section{Analytical study}

\section{Estimation of load-carrying capacity of slab specimens}

The yield line method can be used to estimate the ultimate load-carrying capacity of slab specimens under one-way flexure. It has great potential to predict failure load of reinforced concrete slabs based on the inelastic approach (Darwin et al. 2002; Pillai and Menon 2012). Hence, the yield line method was used to estimate the ultimate load-carrying capacity of test specimens.

The specimens were tested under four-point bending. Consequently, the yield line may form anywhere in between load positions or at load positions. The ultimate load-carrying capacity of specimen does not change with the location of yield line. Therefore, in this study, yield line was assumed to be formed at mid-span under one-way flexural action along the transverse direction. It results in dividing the slabs into two equal parts (Fig. 5).

As per the principle of conservation of energy, external work done $\left(W_{\mathrm{E}}\right)$ and internal work done $\left(W_{\mathrm{I}}\right)$ should be equal and were given by:

$W_{\mathrm{E}}=W_{\mathrm{I}}$,

$\frac{2}{3} P_{\mathrm{u}} \delta_{\mathrm{u}}=\frac{4 m \delta_{\mathrm{u}}}{l_{\mathrm{e}}}$ 
Table 1 Mix proportion of concrete and cube test result

\begin{tabular}{|c|c|c|c|c|c|c|}
\hline \multirow[t]{3}{*}{ Specimen } & \multicolumn{4}{|c|}{ Weight ratio $\left(\mathrm{kg} / \mathrm{m}^{3}\right)$} & \multicolumn{2}{|c|}{ Strength $\left(\mathrm{N} / \mathrm{mm}^{2}\right)$} \\
\hline & \multirow[t]{2}{*}{ Cement } & \multicolumn{2}{|c|}{ Aggregate } & \multirow[t]{2}{*}{ Water } & \multirow[t]{2}{*}{ Design } & \multirow[t]{2}{*}{ Actual } \\
\hline & & Fine & Course & & & \\
\hline With sphere void & 310 & 697 & 1394 & 171 & 25 & 25.7 \\
\hline With cuboid void & & & & & & 26.1 \\
\hline
\end{tabular}

Table 2 Mechanical properties of reinforcement

\begin{tabular}{llllllll}
\hline $\begin{array}{l}\text { Diameter of rein- } \\
\text { forcement }(\mathrm{mm})\end{array}$ & \multicolumn{2}{l}{ Strength $\left(\mathrm{N} / \mathrm{mm}^{2}\right)$} & & \multicolumn{2}{l}{ Strain } & Ductility ratio \\
\cline { 2 - 3 } & Nominal & Yield & Tensile & & Yield & Ultimate & \\
\hline 6 & 500 & 560 & 650 & & 0.0033 & 0.0591 & 17.91 \\
12 & 500 & 585 & 670 & & 0.0035 & 0.1084 & 30.97 \\
\hline
\end{tabular}

where $\delta_{\mathrm{u}}$ is the deflection at centre of slab under the ultimate load $\left(P_{\mathrm{u}}\right), m$ is the in-plane moment for width $b$ and $l_{\mathrm{e}}$ is the effective length.

The ultimate load-carrying capacity $\left(P_{\mathrm{u}}\right)$ of the slab specimen was calculated by Eq. (2) and given by:

$P_{\mathrm{u}}=\frac{6 m}{l_{\mathrm{e}}}$

Similarly, for the self-weight of slab which is uniformly distributed over the span, the relation between self-weight $\left(W_{\mathrm{DL}}\right)$ and in-plane moment $\left(m_{\mathrm{DL}}\right)$ can be derived as:

$W_{\mathrm{DL}}=\frac{8 m_{\mathrm{DL}}}{l_{\mathrm{e}}}$.

Based on the stress-strain relationship of concrete given in IS 456, linear strain variation along the depth of slab, slab specimen dimensions (Fig. 2) and materials' properties (Tables 1,2$)$, the ultimate load-carrying capacity $\left(P_{\mathrm{u}}\right)$ of solid slab is estimated and given in Table 3 .

\section{Flexural stiffness}

Flexural stiffness is defined as the ratio of load and its corresponding deflection. In this study, the secant stiffness of void slab specimens was calculated (Eq. 5) and compared against that of solid slab at yield load.

$K_{\mathrm{y}}=\frac{P_{\mathrm{y}}}{\delta_{\mathrm{y}}}$

The deflection at the centre of slab $\left(\delta_{\mathrm{c}}\right)$ under two-point load of intensity $P / 2$ each (Fig. 5) can be calculated using Eq. (6a).

$\delta_{\mathrm{c}} \approx \frac{P l_{\mathrm{e}}^{3}}{56 E I}$, where $l_{\mathrm{e}}$ is the effective length, $E$ is the modulus of elasticity of material and $I$ is the moment of inertia of a section.

Similarly, for the self-weight of slab which is uniformly distributed over the span, the deflection at the centre of slab $\left(\delta_{\mathrm{c}, \mathrm{DL}}\right)$ can be calculated using Eq. $(6 \mathrm{~b})$.

$\delta_{\mathrm{c}, \mathrm{DL}}=\frac{5 W_{\mathrm{DL}} l_{\mathrm{e}}^{3}}{384 E I}$.

As per IS 456, the short-term deflection was calculated using short-term modulus of elasticity of concrete $\left(E_{\mathrm{c}}=5000\right.$ $\left.f_{\mathrm{ck}}^{0.5}\right)$ and effective moment of inertia $\left(I_{\text {eff }}\right)($ Eq. 7$)$.

$I_{\text {eff }}=\frac{I_{\mathrm{r}}}{1.2-\frac{M_{\mathrm{r}}}{M} \frac{z}{d}\left(1-\frac{x}{d}\right) \frac{b_{\mathrm{w}}}{b}} ; \quad I_{\mathrm{r}} \leq I_{\text {eff }} \leq I_{\mathrm{gr}}$

where $I_{\mathrm{r}}$ is the moment of inertia of cracked section, $M_{\mathrm{r}}$ is the cracking moment (Eq. 8), $M$ is the maximum moment under service load, $z$ is the lever arm distance, $x$ is the depth of neutral axis, $d$ is the effective depth, $b_{\mathrm{w}}$ is the breadth of web and $b$ is the breadth of compression face, and $I_{\mathrm{gr}}$ is the moment of inertia of gross section about the centroidal axis ignoring reinforcement.

$M_{\mathrm{r}}=\frac{f_{\mathrm{cr}} I_{\mathrm{gr}}}{y_{\mathrm{t}}}$,

where $f_{\mathrm{cr}}\left(=0.7 f_{\mathrm{ck}}^{0.5}\right)$ is the modulus of rupture of concrete, and $y_{\mathrm{t}}$ is the distance from centroidal axis of gross section to extreme fibre in tension ignoring reinforcement.

Estimate of deflection based on IS 456 resulted in a larger value. Therefore, the cracking moment $\left(M_{\mathrm{r}}\right)$ may be reduced approximately by $30 \%$ (Pillai and Menon 2012) to estimate deflection based on Eqs. (6a, 6b). The effective moment of inertia of voided slab is calculated based on the critical cross-section that corresponds to the section located in the centre of void as shown in Fig. 6a, b. The uncracked moment 


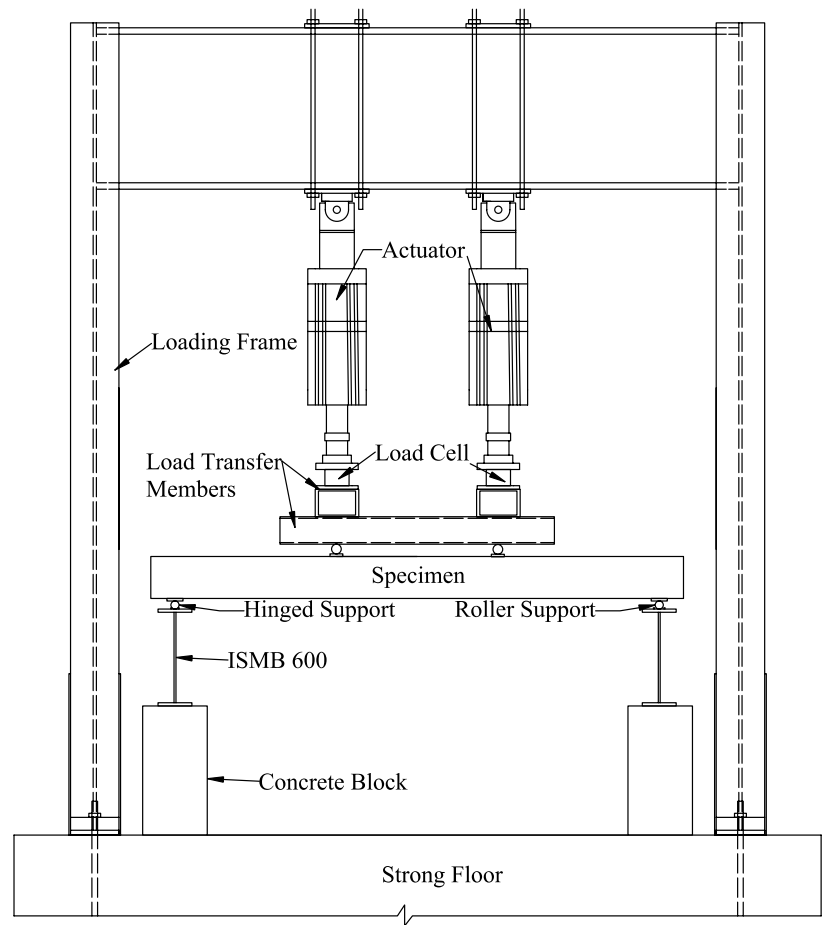

(a)

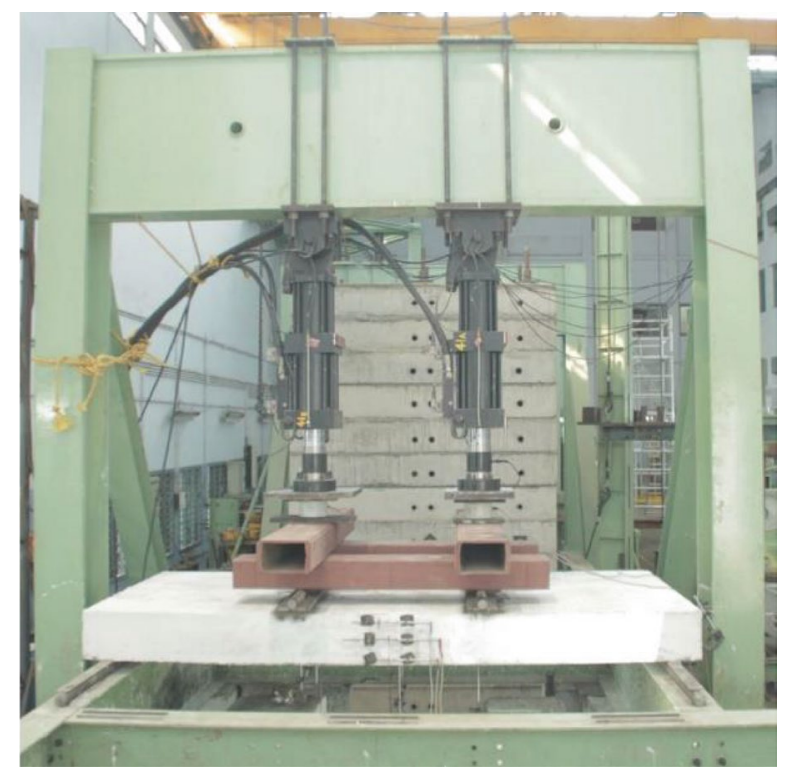

(b)

Fig. 3 a Schematic diagram of experimental test setup (four-point bending test). b Photograph of experimental test setup (four-point bending test)

of inertia $\left(I_{g, V}\right)$ was calculated using Eqs. (9) and (10) for sphere-shaped voided slab and using Eqs. (9) and (11) for cuboid-shaped voided slab, accounting for loss of concrete due to voids. The location of centre of gravity from base $\left(C_{\mathrm{y}}\right)$ was calculated for sphere- and cuboid-shaped voids

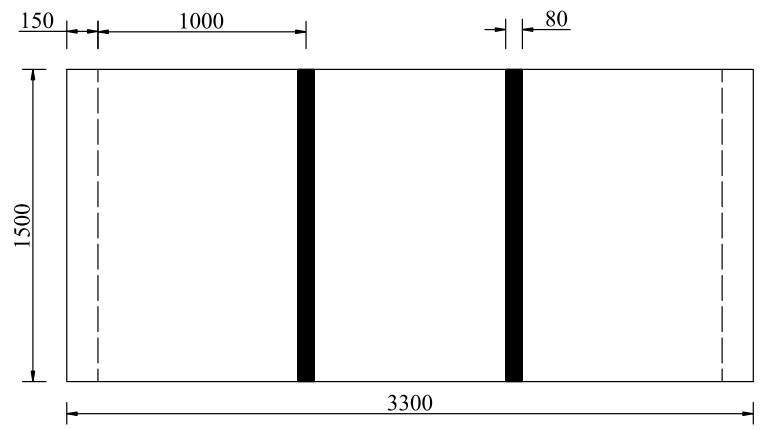

(a) Load position

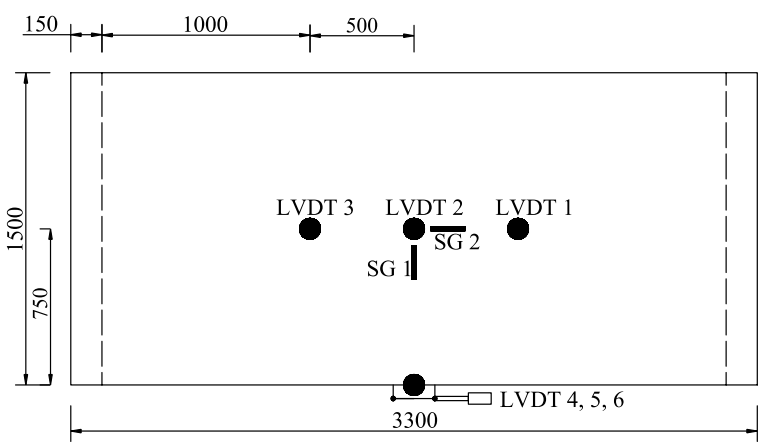

(b) LVDTs and strain gauge location (plan)

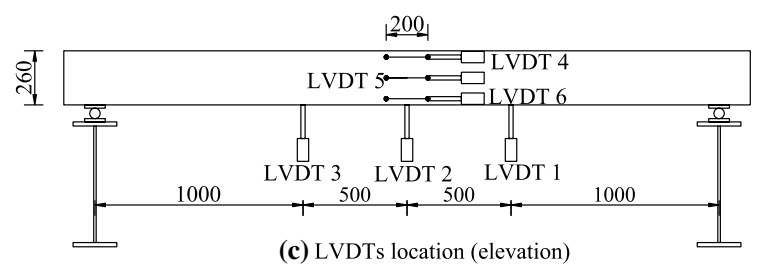

All dimensions are in $\mathrm{mm}$

Fig. 4 Instrumentation of the test specimen

using Eqs. (12) and (13), respectively. Researchers suggested that the cracked moment of inertia of voided slab $\left(I_{\mathrm{r}, \mathrm{V}}\right)$ may be taken as $90 \%$ of the cracked moment of inertia of solid slab $\left(I_{\mathrm{r}, \text { Solid }}\right)$ (BubbleDeck Technology 2008; Midkiff 2013). However, the ratio of $I_{\mathrm{r}, \mathrm{V}}$ to $I_{\mathrm{r}, \text { Solid }}$ needs to be arrived based on the maximum void ratio at a section $(\alpha)$ as given in Eq. (14).

$I_{\mathrm{g}, \mathrm{V}}=I_{\mathrm{g}, \text { Solid }}-n\left(I_{\mathrm{V}}\right)$,

$I_{\mathrm{V}, \mathrm{S}}=\frac{\pi d^{\prime 4}}{64}+\frac{\pi d^{\prime 2}}{4}\left(\frac{D}{2}-C_{\mathrm{y}, \mathrm{S}}\right)^{2}$,

$I_{\mathrm{V}, \mathrm{C}}=\frac{h^{3}}{36}\left(\frac{a^{\prime 2}+4 a^{\prime} a^{\prime \prime}+a^{\prime \prime 2}}{a^{\prime}+a^{\prime \prime}}\right)+\frac{h\left(a^{\prime}+a^{\prime \prime}\right)}{2}\left(\frac{D}{2}-C_{\mathrm{y}, \mathrm{C}}\right)^{2}$,

$C_{\mathrm{y}, \mathrm{S}}=c+\frac{d^{\prime}}{2}$, 


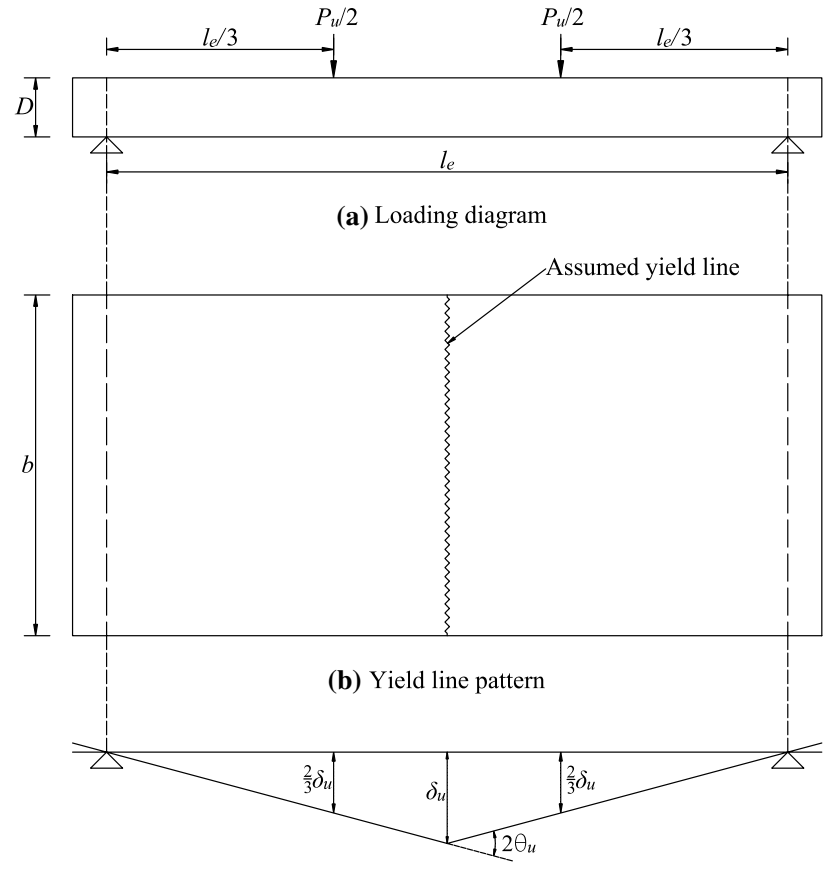

(c) Virtual displacement at collapse (elevation)

\section{Results and discussions}

\section{Load deflection behaviour}

The tested voided slab specimens showed typical flexural behaviour under one-way bending. Initially, specimens remained elastic until cracking followed by inelastic actions such as yielding of bottom reinforcements and ultimate failure by crushing of concrete at the top of the slab. Load versus mid-span deflection of specimens with the sphere and cuboid void showed ductile behaviour (Fig. 7).

\section{Crack pattern}

Figures 8 and 9 show the observed crack pattern on the front elevation of slab specimens. The cracks were formed between loading positions along the width of slab.

\section{Load-carrying capacity}

The load-carrying capacity of voided slabs was similar to solid slab. Load and mid-span deflection corresponding to yield and ultimate stages are summarised in Table 3. The ultimate load from the test specimens is compared with theo-

Fig. 5 Yield line pattern in a one-way simply supported slab

\begin{tabular}{|c|c|c|c|c|c|c|c|}
\hline \multirow[t]{2}{*}{ Sl. no. } & \multirow[t]{2}{*}{ Specimen } & \multicolumn{2}{|l|}{ Yielding } & \multicolumn{2}{|l|}{ Ultimate } & \multirow{2}{*}{$\begin{array}{l}\text { Yielding } \\
K_{\mathrm{y}}(\mathrm{kN} / \mathrm{mm})\end{array}$} & \multirow[t]{2}{*}{$\mu$} \\
\hline & & $P_{\mathrm{y}}(\mathrm{kN})$ & $\delta_{\mathrm{y}}(\mathrm{mm})$ & $P_{\mathrm{u}}(\mathrm{kN})$ & $\delta_{\mathrm{u}}(\mathrm{mm})$ & & \\
\hline \multicolumn{8}{|c|}{ Specimen with sphere-shaped void } \\
\hline 1 & Void (exp.) & 108.3 & 14.16 & 125.4 & 56.21 & 7.65 & 3.97 \\
\hline 2 & Void (theo.) & 88.8 & 14.08 & 119.9 & - & 6.31 & - \\
\hline 3 & Solid (theo.) & 88.8 & 7.27 & 119.9 & - & 12.21 & - \\
\hline \multicolumn{8}{|c|}{ Specimen with cuboid-shaped void } \\
\hline 4 & Void (exp.) & 110.3 & 15.40 & 127.2 & 66.72 & 7.16 & 4.33 \\
\hline 5 & Void (theo.) & 106.4 & 17.81 & 127.4 & - & 5.97 & - \\
\hline 6 & Solid (theo.) & 106.4 & 9.35 & 127.4 & - & 11.38 & - \\
\hline
\end{tabular}

$P_{\mathrm{y}}$ and $P_{\mathrm{u}}$ are the loads corresponding to yielding and ultimate stages, respectively; $\delta_{\mathrm{y}}$ and $\delta_{\mathrm{u}}$ are deflection at mid-span corresponding to yield and ultimate loads, respectively; $K_{\mathrm{y}}$ is secant stiffness corresponding to yield load; and $\mu$ is displacement-ductility ratio

$C_{\mathrm{y}, \mathrm{C}}=\left(\frac{D-h}{2}\right)+\frac{h}{3}\left(\frac{2 a^{\prime}+a^{\prime \prime}}{a^{\prime}+a^{\prime \prime}}\right)$,

$I_{\mathrm{r}, \mathrm{V}}=(1-\alpha) I_{\mathrm{r}, \text { Solid }}$,

where $I_{\mathrm{g}, \text { Solid }}$ is the uncracked moment of inertia of solid slab and $n$ is the number of voids in a section. The theoretical results of mid-span deflection and moment of inertia for voided and solid slabs are summarised in Table 5. retically estimated ultimate load of the solid slab (Tables 3, 4). Self-weight correction based on initial stiffness is applied in load-deflection plot (Fig. 7) and values (Table 3). The ultimate load-carrying capacity of specimens with sphereand cuboid-shaped voids was equal to that of the solid slab. The theoretical load-carrying capacity estimated using the yield line theory of solid and voided slabs was the same, as the contribution from concrete below the neutral axis is ignored. Thus, the yield line theory is applicable to voided slab similar to conventional solid slab. 


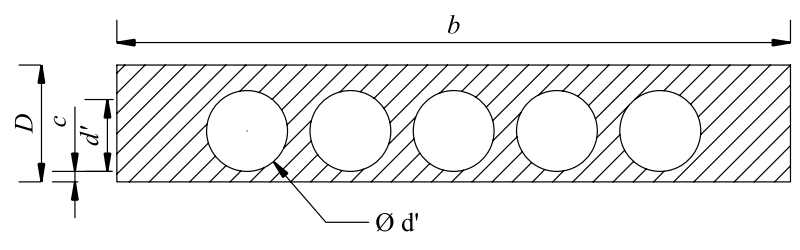

(a) Specimen with sphere shape void former

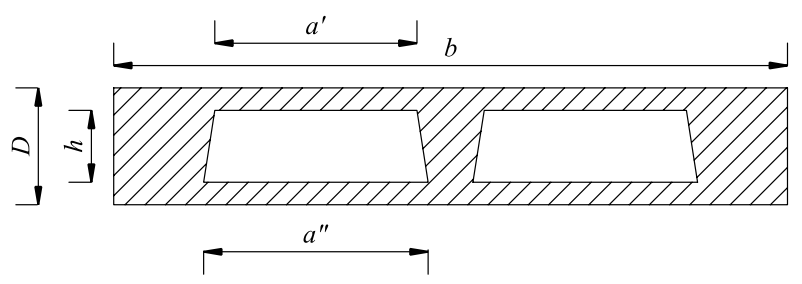

(b) Specimen with cuboid shape void former

Fig. 6 Voided slab sections used to calculate moment of inertia

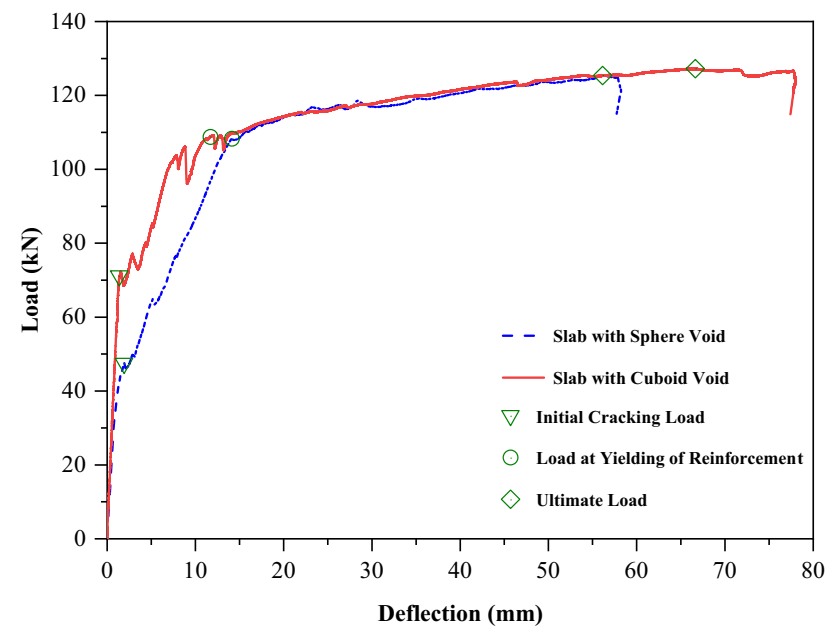

Fig. 7 Load versus mid-span deflection behaviour of test specimens

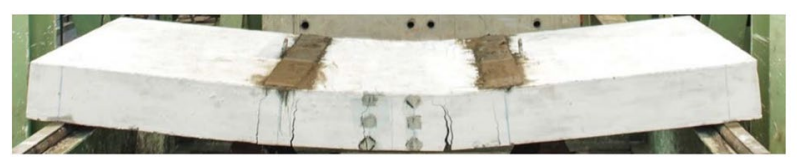

(a) Front elevation (isometric)

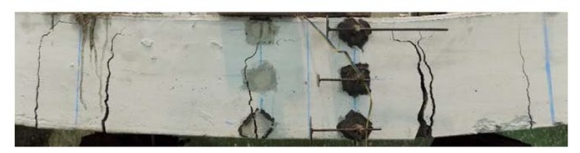

(b) Front elevation (focused)

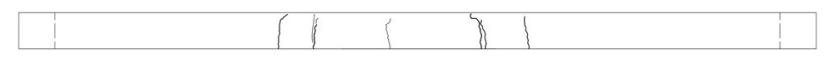

(c) Front elevation (digitised)

Fig. 8 Observed crack pattern of slab specimen with sphere-shaped void

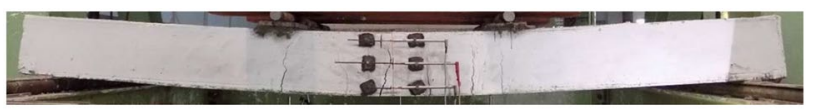

(a) Front elevation

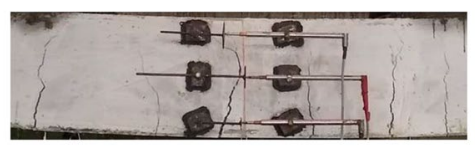

(b) Front elevation (focused)

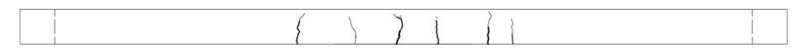

(c) Front elevation (digitised)

Fig. 9 Observed crack pattern of slab specimen with cuboid-shaped void

\section{Flexural stiffness}

Table 5 shows the theoretical estimate of moment of inertia of solid and voided slabs. The ratio of theoretical estimate of effective moment of inertia of solid and voided slabs corresponding to yield load is 0.52 and 0.53 for sphere and cuboid shapes, respectively. These effective moments of inertia showed a similar trend as observed based on experimental result in terms of secant stiffness (Table 4). Ultimately, the loss in cross-sectional area caused by the voids should be considered to estimate the flexural stiffness of the voided slab. In this study, the loss of cross-sectional area was calculated to be $33 \%$ and $39 \%$ for sphere- and cuboid-shaped voids, respectively.

\section{Deflection}

The load-deflection behaviour of the voided slab specimens is shown (Figs. 10, 11). It is observed that the deflection measured at loading positions (LVDTs 1 and 3) matches with each other. It shows that the deflection was equal at any instant of the applied load. The measured deflections along longitudinal direction of slab using LVDTs 1, 2 and 3 were compared at five different loading stages such as $0.20 P_{\mathrm{u}}$, $0.40 P_{\mathrm{u}}, 0.60 P_{\mathrm{u}}, 0.80 P_{\mathrm{u}}$, and $1.0 P_{\mathrm{u}}$. A typical deflection profile of specimens with sphere and cuboid void shapes in the longitudinal direction is shown in Figs. 12 and 13 at different loading stages. It is observed that more than $75 \%$ of ultimate load lies within the serviceable deflection limit of $l_{\mathrm{e}} / 250$ as per IS 456 , i.e., $12 \mathrm{~mm}$.

\section{Strain of bottom reinforcement}

Usually, the material and section properties of reinforced concrete member decide its behaviour. In this section, strain in bottom reinforcements at the centre along both directions is examined. It was observed that strain in the reinforcement 
Table 4 Comparison between experimental and theoretical studies

Table 5 Theoretical estimate of moment of inertia

\begin{tabular}{lllll}
\hline S1. no. & Specimen & \multicolumn{2}{c}{ Flexural stiffness at yielding } & \multicolumn{2}{c}{\begin{tabular}{c} 
Load at ultimate failure \\
\cline { 3 - 5 }
\end{tabular}} & $K_{\mathrm{y} \text {,exp. }} / K_{\mathrm{y}, \text { theo. }}$ & $K_{\mathrm{y}, \text { theo }} / K_{\mathrm{y}, \text { solid }}$ & $P_{\mathrm{u} \text {,exp. }} / P_{\mathrm{u}, \text { solid }}$ \\
\hline 1 & Sphere-shaped void & 1.21 & 0.52 & 1.05 \\
2 & Cuboid-shaped void & 1.20 & 0.53 & 1.00 \\
\hline
\end{tabular}

\begin{tabular}{|c|c|c|c|c|}
\hline \multirow{2}{*}{ Sl. no. } & \multirow[t]{2}{*}{ Specimen } & \multicolumn{3}{|l|}{ Moment of inertia } \\
\hline & & Uncracked, $I_{\mathrm{g}}\left(\mathrm{mm}^{4}\right)$ & Cracked, $I_{\mathrm{r}}\left(\mathrm{mm}^{4}\right)$ & $\begin{array}{l}\text { Effective (at } \\
\text { yield load), } I_{\text {eff }} \\
\left(\mathrm{mm}^{4}\right)\end{array}$ \\
\hline \multicolumn{5}{|c|}{ Specimen with sphere-shaped void } \\
\hline 1 & Void & $18.85 \times 10^{8}$ & $0.734 \times 10^{8}$ & $1.199 \times 10^{8}$ \\
\hline 2 & Solid & $21.97 \times 10^{8}$ & $1.096 \times 10^{8}$ & $2.325 \times 10^{8}$ \\
\hline Ratio & & 0.86 & 0.67 & 0.52 \\
\hline \multicolumn{5}{|c|}{ Specimen with cuboid-shaped void } \\
\hline 3 & Void & $18.73 \times 10^{8}$ & $0.766 \times 10^{8}$ & $1.128 \times 10^{8}$ \\
\hline 4 & Solid & $21.97 \times 10^{8}$ & $1.255 \times 10^{8}$ & $2.148 \times 10^{8}$ \\
\hline Ratio & & 0.85 & 0.61 & 0.53 \\
\hline
\end{tabular}

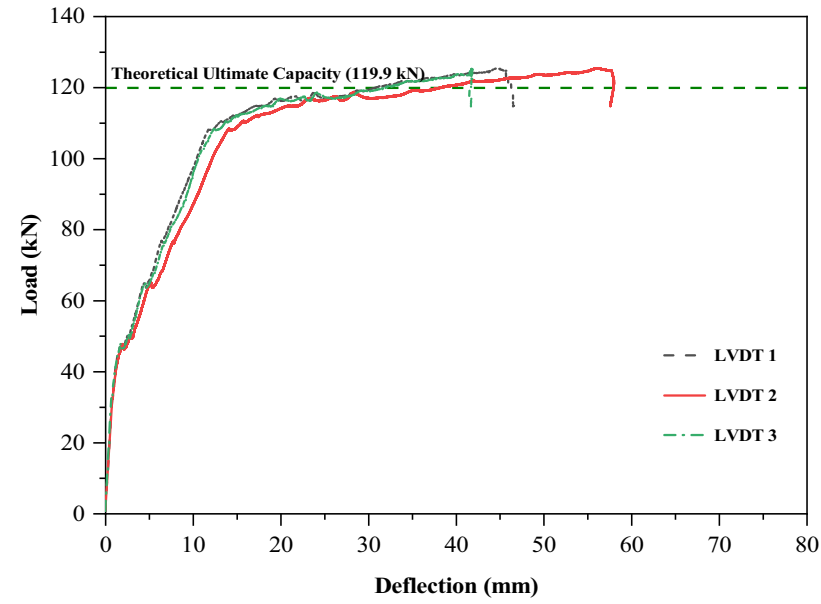

Fig. 10 Load versus deflection behaviour of specimen with sphereshaped void

along transverse direction is zero. It indicates one-way flexural behaviour during entire duration of loading and does not influence the load-carrying capacity (Figs. 14, 15). The presence of void formers did not affect the behaviour of the biaxial voided slab.

\section{Strain of concrete surface along depth of slab}

The concrete surface strain was measured along the depth of slab at three locations at the centre, bottom and top reinforcement levels using LVDTs 4-6. At mid-span of

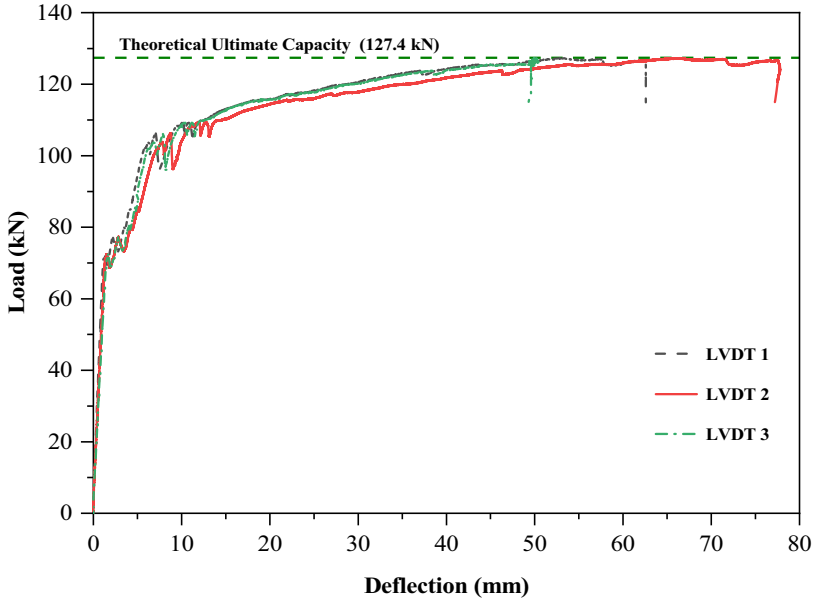

Fig. 11 Load versus deflection behaviour of specimen with cuboidshaped void

slab, these measurements were taken, where the influence of shear due to applied external load is zero. The load versus concrete surface strain along depth of slab of specimens with sphere- and cuboid-shaped voids showed that bottom and top reinforcements were in tension, which was evident through theoretical calculation as well. Hence, it is understood that the neutral axis of voided slab lies in the cover concrete to top reinforcement (Figs. 16, 17). In Fig. 16, results of LVDT 6 are not presented, as this LVDT malfunctioned during the test. 


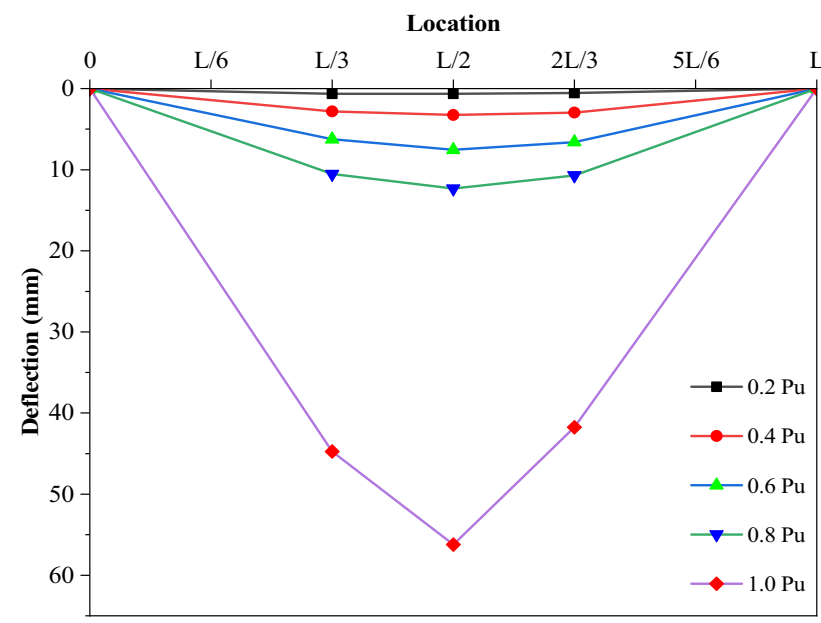

Fig. 12 Deflection profile of specimen with sphere-shaped void

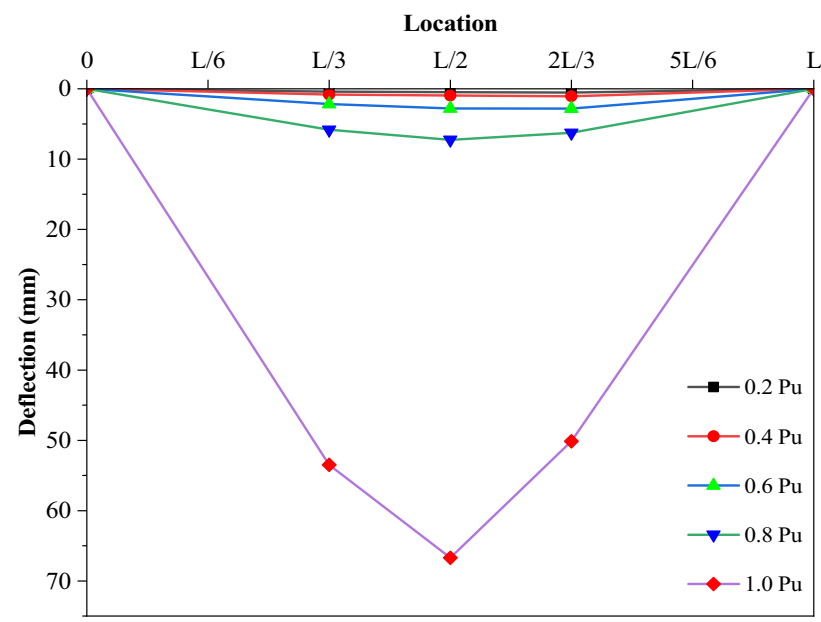

Fig. 13 Deflection profile of specimen with cuboid-shaped void

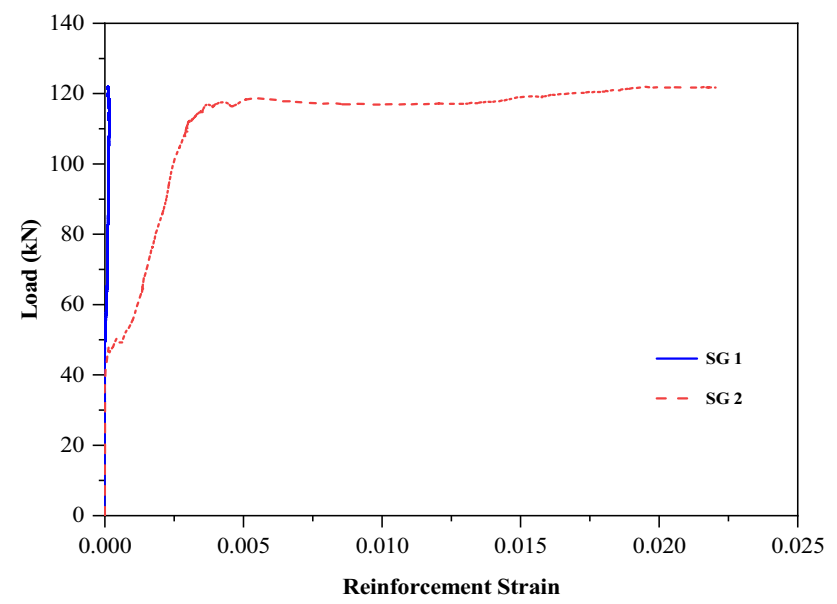

Fig. 14 Load versus strain of bottom reinforcement of specimen with sphere-shaped void

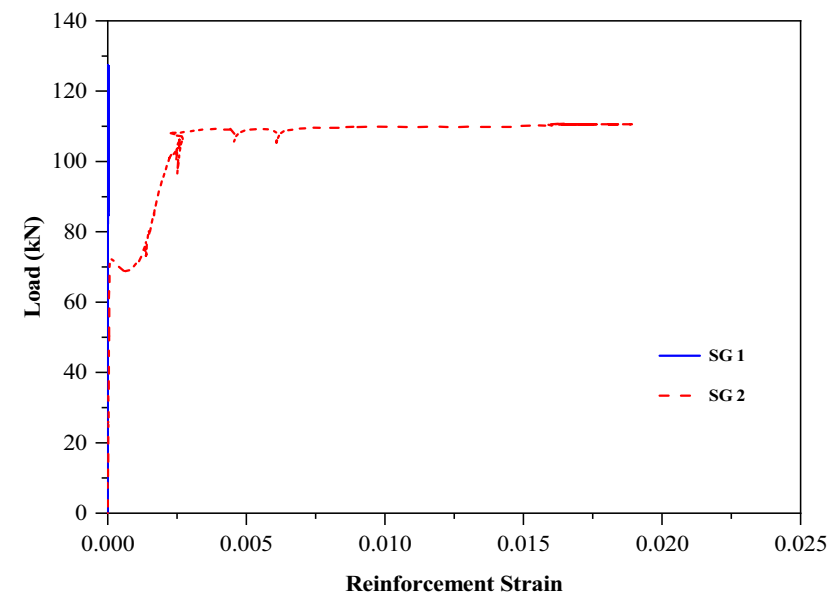

Fig. 15 Load versus strain of bottom reinforcement of specimen with cuboid-shaped void

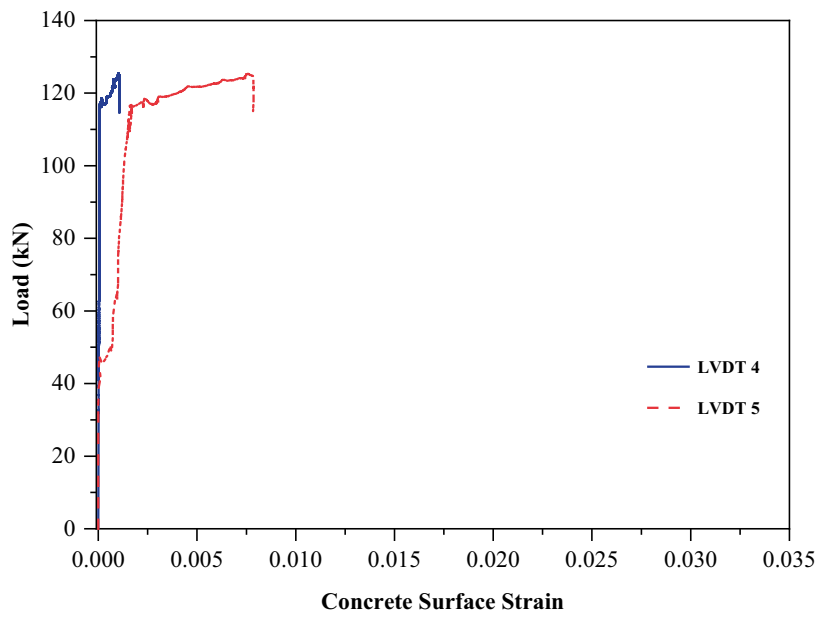

Fig. 16 Load versus concrete surface strain along depth of slab specimen with sphere void

\section{Displacement ductility ratio}

Load-deflection behaviour of the voided slab specimens shows predominantly ductile and flexural response. The displacement ductility ratio $(\mu)$ of voided slab specimens was calculated using Eq. (15) and found to be 3.97 and 4.33 for specimens with sphere- and cuboid-shaped voids, respectively. The results are summarised in Table 3.

$\mu=\frac{\delta_{\mathrm{u}}}{\delta_{\mathrm{y}}}$ 


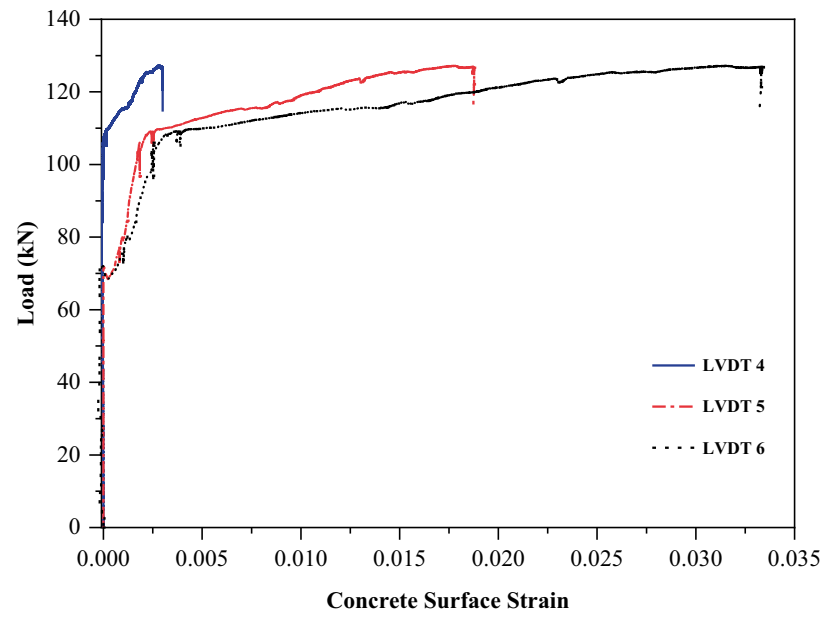

Fig. 17 Load versus concrete surface strain along depth of slab specimen with cuboid void

\section{Summary and conclusion}

Structural behaviour of the voided slab specimens was studied considering parameters such as load versus deflection behaviour, crack pattern, load-carrying capacity, flexural stiffness, deflection profile, load versus strain behaviour of bottom reinforcement and concrete surface along the depth of slab, and displacement-ductility ratio. The applicability of existing IS 456 code provisions for design and/or analysis of biaxial voided slab is verified. The following observations are drawn based on experimental and analytical investigations of biaxial voided slab (with sphere- and cuboid-shaped voids):

1. The voided slabs show typical flexure behaviour similar to that of the solid slab. The cracks were observed in the region of pure bending and distributed along the longitudinal direction. The voided slab specimen exhibited a well-defined failure mechanism with the yield of bottom reinforcements and crushing of concrete at the top of slab surface.

2. The ultimate load-carrying capacity of specimens with sphere- and cuboid-shaped voids was equal to that of the solid slab. The theoretical load-carrying capacity of voided and solid slabs using the yield line theory was the same. Thus, the yield line theory can be adopted for estimation of the load-carrying capacity of voided slabs.

3. The effective moment of inertia at yield load of voided specimens with sphere- and cuboid-shaped voids was obtained as 52 and $53 \%$ of solid slab, respectively. It shows that the loss of cross-section due to voids should be considered for calculating flexural stiffness of voided slab.
4. The presence of void formers did not influence the reinforcement behaviour in longitudinal and transverse directions.

5. The concrete surface strain along depth of slab evidenced that the neutral axis of voided slab lies in the cover concrete to top reinforcement.

6. The one-way flexure behaviour of voided slabs was very well predicted by the yield line theory and provisions of IS 456 accounted for necessary corrections required for loss of cross-sectional area due to voids.

Acknowledgements This work was supported by Science and Engineering Research Board, Department of Science and Technology, India (SR/S3/MERC/0040/2012) and M/s Post Tension Services India Pvt. Ltd. (PTSI), Vadodara, Gujarat, India (WO/GEN/0001/16-17). The authors wish to acknowledge the assistance and facilities offered by Technical Staff, Structural Engineering Laboratory, IIT Madras.

Open Access This article is distributed under the terms of the Creative Commons Attribution 4.0 International License (http://creativeco mmons.org/licenses/by/4.0/), which permits unrestricted use, distribution, and reproduction in any medium, provided you give appropriate credit to the original author(s) and the source, provide a link to the Creative Commons license, and indicate if changes were made.

\section{References}

Björnson G (2003) BubbleDeck-two-way hollow slab. www.bubbl edeck-uk.com

BubbleDeck Technology (2008) BubbleDeck voided flat slab solutions-technical manual and documents. www.bubbledeck-uk. com

Chung JH, Park JH, Choi HK et al (2010) An analytical study on the impact of hollow shapes in bi-axial hollow slabs. In: FraMCoS-7. Korea Concrete Institute, pp 1729-1736

Daliform Group (2014) U-Boot Beton ${ }^{\circledR}$ system study: lightened concrete slab by using U-Boot Beton ${ }^{\circledR}$. www.daliform.com

Darwin D, Dolan C, Nilson A (2002) Design of concrete structures, 15 th edn. McGraw-Hill, New York

Harding P (2004) BubbleDeck ${ }^{\mathrm{TM}}$ —advanced structure engineering. BubbleDeck Artic. pp 15-16. www.bubbledeck.com

Ibrahim AM, Ali NK, Salman WD (2013) Flexural capacities of reinforced concrete two-way bubbledeck slabs of plastic spherical voids. Diyala J Eng Sci 06:9-20

IS 1786 (2008) High strength deformed steel bars and wires for concrete reinforcement-specification. Bureau of Indian Standards, New Delhi

IS 456 (2000) Plain and reinforced concrete - code of practice. Bureau of Indian Standards, New Delhi

Kim SH (2011) Flexural behavior of void RC and PC slab with polystyrene forms. Key Eng Mater 452-453:61-64. https://doi. org/10.4028/www.scientific.net/KEM.452-453.61

Kim BH, Chung JH, Choi HK et al (2011) Flexural capacities of oneway hollow slab with donut type hollow sphere. Key Eng Mater 452-453:773-776. https://doi.org/10.4028/www.scientific.net/ KEM.452-453.773

Matešan D, Radnić J, Grgić N, Čamber V (2012) Strength capacity of square reinforced concrete slabs. Mater Sci Eng 43:399-404. https ://doi.org/10.1002/mawe.201200972 
Midkiff CJ (2013) Plastic voided slab systems: applications and design. MS thesis, Kansas State University, Manhattan

Pillai SU, Menon D (2012) Reinforced concrete design, 3rd edn. Tata McGraw Hill, New Delhi

Valivonis J, Jonaitis B, Zavalis R et al (2014) Flexural capacity and stiffness of monolithic biaxial hollow slabs. J Civ Eng Manag 20:693-701. https://doi.org/10.3846/13923730.2014.917122
Publisher's Note Springer Nature remains neutral with regard to jurisdictional claims in published maps and institutional affiliations. 